\title{
Costs of cancer care for use in economic evaluation: a UK analysis of patient-level routine health system data
}

P S Hall ${ }^{\star}, 1,2$, P Hamilton ${ }^{3}$, C T Hulme ${ }^{1}$, D M Meads ${ }^{1}, \mathrm{H} \mathrm{Jones}^{4}$, A Newsham ${ }^{4}$, J Marti ${ }^{1}$, A F Smith ${ }^{1}, \mathrm{H} \mathrm{Mason}^{5}$, G Velikova ${ }^{4}$, L Ashley $^{6}$ and P Wright ${ }^{4}$

${ }^{1}$ Academic Unit of Health Economics, University of Leeds, Charles Thackrah Building, 101 Clarendon Road, Woodhouse, Leeds LS2 9LJ, UK; ${ }^{2}$ St James Institute of Oncology, Leeds, Bexley Wing, St James University Hospital, Beckett Street, Leeds, West Yorkshire LS9 7TF, UK; ${ }^{3}$ Manchester Royal Infirmary, Manchester Institute of Nephrology and Transplantation, Oxford Road, Manchester M139WL, UK; ${ }^{4}$ Leeds Institute of Cancer and Pathology, University of Leeds, Bexley Wing, St James University Hospital, Beckett Street, Leeds, West Yorkshire LS9 7TF, UK; ${ }^{5}$ Sheffield Teaching Hospitals NHS Foundation Trust, Herries Road,

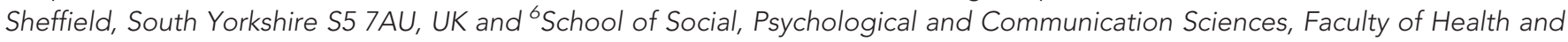
Social Sciences, Leeds Beckett University, Calverley Building, City Campus, Leeds LS1 3HE, UK

Background: The rising financial burden of cancer on health-care systems worldwide has led to the increased demand for evidence-based research on which to base reimbursement decisions. Economic evaluations are an integral component of this necessary research. Ascertainment of reliable health-care cost and quality-of-life estimates to inform such studies has historically been challenging, but recent advances in informatics in the United Kingdom provide new opportunities.

Methods: The costs of hospital care for breast, colorectal and prostate cancer disease-free survivors were calculated over 15 months from initial diagnosis of cancer using routinely collected data within a UK National Health Service (NHS) Hospital Trust. Costs were linked at patient level to patient-reported outcomes and registry-derived sociodemographic factors. Predictors of cost and the relationship between costs and patient-reported utility were examined.

Results: The study population included 223 breast cancer patients, 145 colorectal and 104 prostate cancer patients. The mean 15-month cumulative health-care costs were £12595 (95\% Cl £11517-£13722), £12643 (£11 282-£14 102) and £3722 (£3263-£4208), per-patient respectively. The majority of costs occurred within the first 6 months from diagnosis. Clinical stage was the most important predictor of costs for all cancer types. EQ-5D score was predictive of costs in colorectal cancer but not in breast or prostate cancer.

Conclusion: It is now possible to evaluate health-care cost using routine NHS data sets. Such methods can be utilised in future retrospective and prospective studies to efficiently collect economic data.

The cost of cancer is much discussed and of considerable relevance internationally given rising health-care costs and financial constraint. The initial treatment period, rehabilitation and early follow-up after a new diagnosis of cancer incurs heavy resource demands on secondary care. Characterisation and prediction of these costs alongside other health outcomes is important for health-care budget planning and service design, aiming at improved efficiency. In particular, economic evaluation is increasingly used to inform the allocation of scarce health resources, and many national reimbursement bodies (including the National Institute for Health and Care Excellence (NICE) in the United Kingdom) require the use of patient quality-adjusted life-years (QALYs) as an endpoint in economic evaluations (Drummond et al, 2005). Reliable analyses therefore require robust estimation of

*Correspondence: Dr PS Hall; E-mail: p.s.hall@leeds.ac.uk

Received 13 July 2014; revised 17 November 2014; accepted 1 December 2014; published online 20 January 2015 
costs and patient quality-of-life (QoL). There have been several attempts to describe the cost of cancer using insurance claims, registry data or manual case-note audit (Brown et al, 1999; Karnon et al, 2007; Yabroff et al, 2008; Krahn et al, 2010; Mariotto et al, 2011; Tilson et al, 2012; De Oliveira et al, 2013). Methods applied in the United Kingdom, where detailed claims databases do not exist, either fail to capture local variation and full data granularity or require a heavy data collection burden; accurate and easily reproducible estimates of the true cost of care therefore remain elusive. In the United Kingdom, the National Health Service (NHS) provides universal publically funded health-care, which operates financially through a system of commissioning for services. Payments for defined episodes of care are calculated using a national tariff. In an attempt to improve the accuracy and national standardisation of the methods used to calculate this national tariff, Patient Level Information and Costing Systems (PLICS) are being developed (Francisci et al, 2013). Local pilots promoting national standardisation of methods using PLICS are on-going, under guidance from the Department of Health. It is hoped that such systems, if fully implemented, will promote the ability to generate efficiency savings through improved service evaluation and planning (Blunt and Bardsley, 2012; Vogl, 2012). Patient-levelcosting systems provide new opportunities for the calculation of the complete hospital-based cost of care. By accurately capturing patient-level variation they offer an improvement over current methods, which rely on coded Human Resource Groups (HRGs) and assigned national standard tariffs.

It is now accepted that the assessment of patient's QoL should be embedded in routine care (Black, 2013). The NHS Patient Reported Outcome Measures (PROMS) initiative routinely collects QoL data from a number of patient groups in England and is soon to be rolled out to cancer patients (Glaser et al, 2013). Identifying an efficient method to collect routine PROMs data linked to clinical and financial data sets is an essential prerequisite for robust future economic evaluation of cancer services. The electronic Patient-reported Outcomes from Cancer Survivors (ePOCS) project has designed and tested the technical and clinical feasibility of an electronic system for collecting patient-reported outcome data online and linking this with clinical cancer registry data (Ashley et al, 2011b); through data linkage mechanisms, it is now possible to also connect cost data with PROMS data using this new system.

The primary aim of this paper is to describe the direct costs of hospital-based care for patients following a diagnosis of breast, colorectal or prostate cancer using routine NHS data. In particular, it aims to confirm the feasibility of data linkage between a new patient-level hospital finance system, electronic clinical records and electronically captured PROMs. The resulting composite data set is then used to explore the extent to which clinical and sociodemographic factors predict NHS costs and QoL over a 15-month period.

\section{PATIENTS AND METHODS}

The costs of hospital-based care for breast, colorectal and prostate cancer disease-free survivors were calculated over 15 months from initial diagnosis of cancer using data collected during a feasibility study of the ePOCS system. The ePOCS system is a novel electronic system for collecting patient-reported outcomes online and linking them with clinical cancer registry data. The feasibility study included collection of patient clinical, sociodemographic, cost and QoL data, which were used in this analysis to explore total 15-month cumulative costs, cost predictors and patient utility for disease-free survivors. Comprehensive accounts of the design and development of the ePOCS system, and the protocol and results of the feasibility study have been published open-access (Ashley et al, 2011a, 2013). In brief, English-literate adult patients within 6 months of a diagnosis of early breast, colorectal or prostate cancer being treated with curative intent were recruited from Leeds Teaching Hospitals NHS Trust (LTHT) and Calderdale \& Huddersfield NHS Foundation Trust (CHFT). Eligible patients were identified during routine multidisciplinary meetings and/or through consultation of medical notes by NHS research nurses and/or oncology clinicians. The recruitment period was November 2010 to September 2011. Participants were asked to complete PROMs online using the ePOCS system at three time points: T1, within 6 months of diagnosis, T2 at 9 months post diagnosis and T3 at 15 months post-diagnosis. The PROMs data were linked with patients' clinical registry data and stored in the National Cancer Data Repository.

The cost analysis included all hospital-based costs incurred over the 15-month follow-up period in the LTHT population. Day zero was defined as the date of diagnosis, recorded from the medical notes by the research nurse at the time of patient consent to the ePOCS study. Patients were diagnosed between May 2010 and September 2011. Costs were adjusted to the common base year of 2011-2012 using the Personal Social Services Research Unit (PSSRU) Hospital and community health services pay and prices index. Confidence intervals were calculated for all analyses using the bootstrap method. Analysis of costs was conducted using regression analysis performed on log-costs, which were approximately normally distributed and did not contain zeros, using the ordinary least squares method. The explanatory variables age, gender, oncological stage, Index of Multiple Deprivation (IMD) and baseline EQ-5D (T1) were established a priori; all of which were included in univariate and multivariate analyses. Complete case analysis was used for individual EQ-5D regressions. The complete 15 months of follow-up was available for all patients. Patients who died or suffered a cancer relapse (i.e., ceased to be disease free) during this period were identified from the clinical record and excluded on the grounds that this study reports the outcomes specific to disease-free survivors. All analysis was carried out using the $\mathrm{R}$ statistical software package version 3.0.0 (R Development Core Team 2009).

Data capture and linkage. The cost analysis was based on finance data from patients recruited at LTHT only, owing to the fact that PLICS data were unavailable for patients recruited at CHFT. PROMs data were available from both LTHT and CHFT; the analysis of patient utility therefore utilised data from patients recruited at both LTHT and CHFT.

Clinical data. The LTHT Oncology department uses a computerbased system called Patient Pathway Manager (PPM), which links the various clinical data systems within the LTHT and maintains an electronic patient record. PPM includes information on demographics, pathology, radiology, surgery, chemotherapy and radiotherapy. The ePOCS study information was also held within PPM, allowing internal linkage of ePOCS study ID, NHS number and other identifiers (Newsham et al, 2011).

Finance data. Patient records within LTHT from PPM were individually linked to costs held within the local pilot database of the national PLICS scheme using each patient's NHS number. This provides a cost for hospital-based accident and emergency department visits, outpatient attendances and inpatient stays. Individual care episodes are coded using the national HRG version 4 codes. HRG costing uses a mixture of (a) top-down costing where cost pools (used to collect indirect and overhead costs) are allocated to HRGs using the total cost of that cost pool weighted for each HRG based upon the best available data and, (b) bottomup costing - which builds up the costs of an HRG from known 
local expenditure (e.g., prosthetics in hip replacement) HRGs (Department of Health Payment by Results team, 2012). HRG codes include the average cost of intravenous and oral chemotherapies.

Socioeconomic data. A marker of socioeconomic status was ascertained by calculating IMD scores and quintiles from patients' postcodes recorded in PPM; the first quintile contains patients living in the most deprived areas and the fifth quintile contains patients living in the least deprived areas (Department for Communities and Local Government, 2010).

Patient-reported outcome data. Over the three time points, participants treated at LTHT and CHFT were asked to complete a range of PROMs, which assessed patients' psychosocial and sociodemographic status (e.g., education level, employment status etc.), QoL and disease specific (breast, colorectal and prostate cancer) variables. The analysis presented here utilises PROMs data on patient health status as measured by the EQ-5D version 2 questionnaire, collected at T1, T2 and T3. Complete case analysis was used to maximise reproducibility in future studies that build on this pilot.

The EQ-5D questionnaire measures health status across five domains: mobility, self-care, usual activities, pain/discomfort and anxiety/depression. Respondents specify whether they have no problems, some problems or severe problems within each domain, on the day of response. Utility scores were derived from the EQ-5D responses using preferences for health states elicited from the UK general public (The EuroQol Group, 1990; Gudex et al, 1995). A maximum utility score of 1 represents the state of being in full health; zero represents the state of being dead. The EQ-5D has been used widely in cancer studies (Pickard et al, 2007b), and is regarded as the gold-standard measure of QoL in the United Kingdom as specified by NICE for the calculation of QALYs. We compared patients' utility scores with age- and sex-matched population norms obtained from a survey of the UK population (Kind et al, 1998).
Ethical approval was given for the ePOCS study from the NHS Leeds (East) Research Ethics Committee (10/H1306/65). Patients provided the written informed consent.

\section{RESULTS}

Patient characteristics. In total, there were 636 patients consented into the ePOCS study across LTHT and CHFT. The mean patient age was 63 (range 23-92). Full details of the patient demographics and baseline characteristics are available in the open-access ePOCS study feasibility report (Ashley et al, 2013). There were 297 patients with breast cancer, 192 with colorectal cancer and 147 with prostate cancer. Patients not classified as survivors within the 15 -month-study period were excluded; these included patients who developed new primary cancers, recurrent cancer or had died. The final study population meeting eligibility consisted of 223 patients with breast cancer, 145 with colorectal cancer and 104 with prostate cancer from LTHT, and 68 with breast cancer, 19 with colorectal cancer and 36 with prostate cancer from CHFT (see Figure 1). Baseline patient characteristics are described in Table 1. Overall, the mean age was 56 (median 55, s.d. 10.7) for the breast patients, 63 (median 63, s.d. 9.1) for the colorectal patients and 65 (median 65, s.d. 6.6) for the prostate patients. For the cost analysis, complete data were available. For the analysis of patient utility, over $92 \%$ of EQ-5D questionnaires were returned at 6 months across all cancers, however this dropped to around $70 \%$ at 15 months for breast and colorectal cancer, and $82 \%$ for prostate cancer, respectively. Using the NHS number alone, linkage between the LTHT PLICS finance database, the electronic clinical record and the ePOCS study database was $100 \%$.

Hospital costs. Costs for breast and colorectal cancer were similar and considerably higher than those for prostate cancer. For breast cancer patients, the mean cumulative hospital costs at 6,9 and 15 months (with 95\% CIs) were $£ 9557$ ( $£ 8893-£ 10220$ ), £11 175 (£10339-£12 059) and £12595 (£11517-£13 722), respectively. For colorectal cancer, the corresponding figures were $£ 10038$

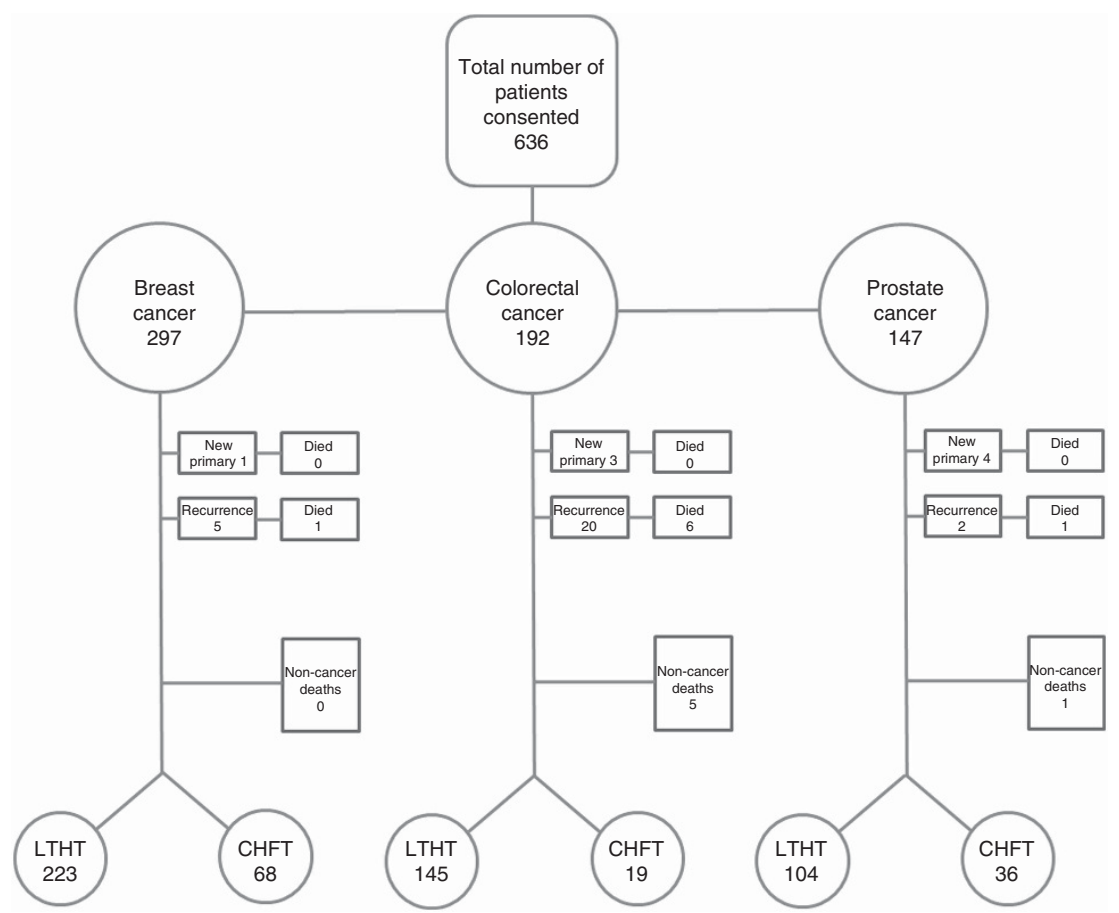

Figure 1. Flowchart describing eligible patients. 
Table 1. Patient characteristics—numbers of patients (\%)

\begin{tabular}{|c|c|c|c|c|c|c|}
\hline \multirow[b]{2}{*}{ Characteristic (\%) } & \multicolumn{2}{|c|}{ Breast } & \multicolumn{2}{|c|}{ Colorectal } & \multicolumn{2}{|c|}{ Prostate } \\
\hline & QOL data & Cost data & QOL data & Cost data & QOL data & Cost data \\
\hline Patients consented & \multicolumn{2}{|c|}{297} & \multicolumn{2}{|c|}{192} & \multicolumn{2}{|c|}{147} \\
\hline Eligible patients & \multicolumn{2}{|c|}{291} & \multicolumn{2}{|c|}{164} & \multicolumn{2}{|c|}{140} \\
\hline Patients analysed & 250 & 223 & 135 & 146 & 130 & 104 \\
\hline \multicolumn{7}{|c|}{ EQ-5D questionnaire returns } \\
\hline $\begin{array}{l}6 \text { months } \\
12 \text { months } \\
15 \text { months }\end{array}$ & $\begin{array}{l}231(92.4) \\
186(74.4) \\
177(70.8)\end{array}$ & & $\begin{array}{r}128(94.8) \\
101(74.8) \\
97(71.9)\end{array}$ & & $\begin{array}{l}126(96.9) \\
109(83.8) \\
106(81.5)\end{array}$ & \\
\hline \multicolumn{7}{|l|}{ Sex } \\
\hline $\begin{array}{l}\text { Male } \\
\text { Female }\end{array}$ & $\begin{array}{c}1(0.4) \\
249(99.6)\end{array}$ & $\begin{array}{c}2(0.9) \\
221(99.1)\end{array}$ & $\begin{array}{l}86(63.7) \\
49(36.3)\end{array}$ & $\begin{array}{l}89(61.0) \\
57(39.0)\end{array}$ & & \\
\hline \multicolumn{7}{|l|}{ Age } \\
\hline $\begin{array}{l}<65 \\
\geqslant 65\end{array}$ & $\begin{array}{r}194(77.6) \\
56(22.4)\end{array}$ & $\begin{array}{r}172(77.1) \\
51(22.9) \\
\end{array}$ & $\begin{array}{l}76(56.3) \\
59(43.7)\end{array}$ & $\begin{array}{l}80(54.8) \\
66(45.2)\end{array}$ & $\begin{array}{l}58(44.6) \\
72(55.4)\end{array}$ & $\begin{array}{l}50(48.1) \\
54(51.9)\end{array}$ \\
\hline \multicolumn{7}{|l|}{ IMD } \\
\hline $\begin{array}{l}1 \\
2 \\
3 \\
4 \\
5\end{array}$ & $\begin{array}{l}48(19.2) \\
45(18.0) \\
33(13.2) \\
71(28.4) \\
53(21.2)\end{array}$ & $\begin{array}{l}47(21.1) \\
42(18.8) \\
28(12.6) \\
58(26.0) \\
48(21.5)\end{array}$ & $\begin{array}{l}25(18 .) \\
30(22.2) \\
24(17.8) \\
30(22.2) \\
26(19.3)\end{array}$ & $\begin{array}{l}32(21.9) \\
31(21.2) \\
25(17.1) \\
34(23.3) \\
24(16.4)\end{array}$ & $\begin{array}{l}14(10.8) \\
21(16.2) \\
24(18.5) \\
36(27.7) \\
35(26.9)\end{array}$ & $\begin{array}{l}12(11.5) \\
16(15.4) \\
20(19.2) \\
28(26.9) \\
28(26.9)\end{array}$ \\
\hline \multicolumn{7}{|l|}{ HER2 status } \\
\hline $\begin{array}{l}\text { Positive } \\
\text { Negative } \\
\text { Unknown }\end{array}$ & $\begin{array}{c}13(5.2) \\
138(55.2) \\
99(39.6) \\
\end{array}$ & $\begin{array}{r}17(7.6) \\
158(70.9) \\
48(21.5) \\
\end{array}$ & & & & \\
\hline \multicolumn{7}{|l|}{ Hormone receptor } \\
\hline $\begin{array}{l}\text { Positive } \\
\text { Negative }\end{array}$ & $\begin{array}{r}158(63.2) \\
92(36.8)\end{array}$ & $\begin{array}{r}139(62.3) \\
84(37.7)\end{array}$ & & & & \\
\hline \multicolumn{7}{|l|}{ Lymph nodes } \\
\hline $\begin{array}{l}\text { NO } \\
\text { N positive } \\
\text { Unknown }\end{array}$ & $\begin{array}{r}125(50.0) \\
47(18.8) \\
78(31.2)\end{array}$ & $\begin{array}{r}140(62.8) \\
57(25.6) \\
26(11.7)\end{array}$ & & & & \\
\hline \multicolumn{7}{|l|}{ Primary tumour } \\
\hline $\begin{array}{l}\text { T1 } \\
\text { T2 } \\
\text { T3 } \\
\text { T4 } \\
\text { Unknown }\end{array}$ & $\begin{aligned} 112 & (44.8) \\
51 & (20.4) \\
6 & (2.4) \\
0 & (0) \\
81 & (32.4)\end{aligned}$ & $\begin{aligned} 133 & (59.6) \\
55 & (24.7) \\
7 & (3.1) \\
0 & (0) \\
28 & (12.6)\end{aligned}$ & & & & \\
\hline \multicolumn{7}{|l|}{ Grade } \\
\hline $\begin{array}{l}1 \\
2 \\
3 \\
\text { Unknown }\end{array}$ & $\begin{array}{r}43(17.2) \\
106(42.4) \\
56(22.4) \\
45(18.0)\end{array}$ & $\begin{array}{l}51(22.9) \\
95(42.6) \\
53(23.8) \\
24(10.8)\end{array}$ & & & & \\
\hline \multicolumn{7}{|l|}{ Dukes staging } \\
\hline $\begin{array}{l}\text { A } \\
\text { B } \\
\text { C } \\
\text { D } \\
\text { Unknown }\end{array}$ & & & $\begin{array}{c}15(11.1) \\
25(18.5) \\
19(14.1) \\
1(0.7) \\
75(55.6)\end{array}$ & $\begin{array}{c}19(13.0) \\
31(21.2) \\
26(17.8) \\
1(0.7) \\
69(47.3)\end{array}$ & & \\
\hline \multicolumn{7}{|l|}{ Gleason score } \\
\hline $\begin{array}{l}0-5 \\
6 \\
7 \\
8 \\
9 \\
10 \\
\text { Unknown }\end{array}$ & & & & & $\begin{array}{c}0(0) \\
36(27.7) \\
60(46.2) \\
2(1.5) \\
9(6.9) \\
0(0) \\
23(17.7)\end{array}$ & $\begin{aligned} 0 & (0) \\
28 & (26.9) \\
56 & (53.8) \\
2 & (1.9) \\
7 & (6.7) \\
0 & (0) \\
11 & (10.6)\end{aligned}$ \\
\hline
\end{tabular}

(£9015-£11 131), £11809 (£10551-£13 109) and £12643 (£11 282-£14 102) and for prostate cancer £2807 (£2398-£3233), $£ 3407$ (£2977-£3846) and £3722 (£3263-£4208). In each cancer, at least $75 \%$ of the total costs at month 15 were incurred by month 6 .
Figure 2 illustrates the decline in costs over time in all cancers with small rises around the 6- and 12-month follow-up visits.

The mean costs by subgroup suggest that the below 65 age group incurred greater costs than the 65 and over group and that 


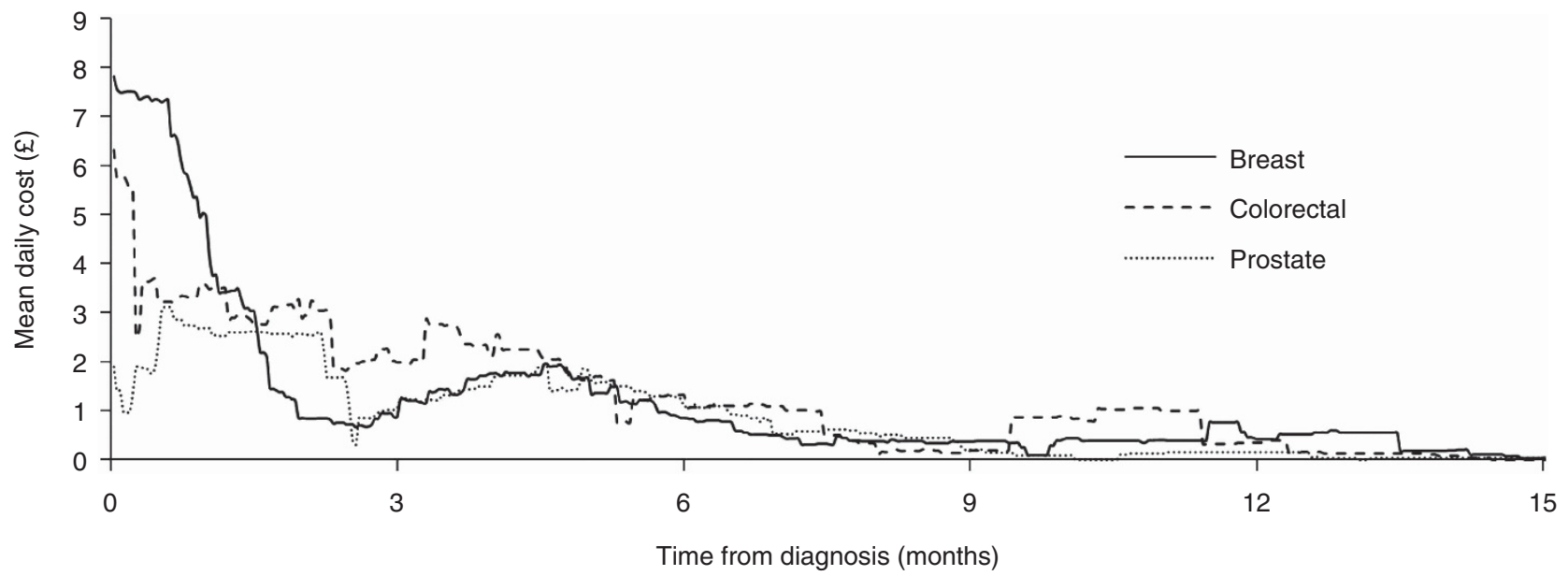

Figure 2. Rolling mean daily cost by cancer site. Each time point represents the average daily cost over the 30 preceding and 30 following days.
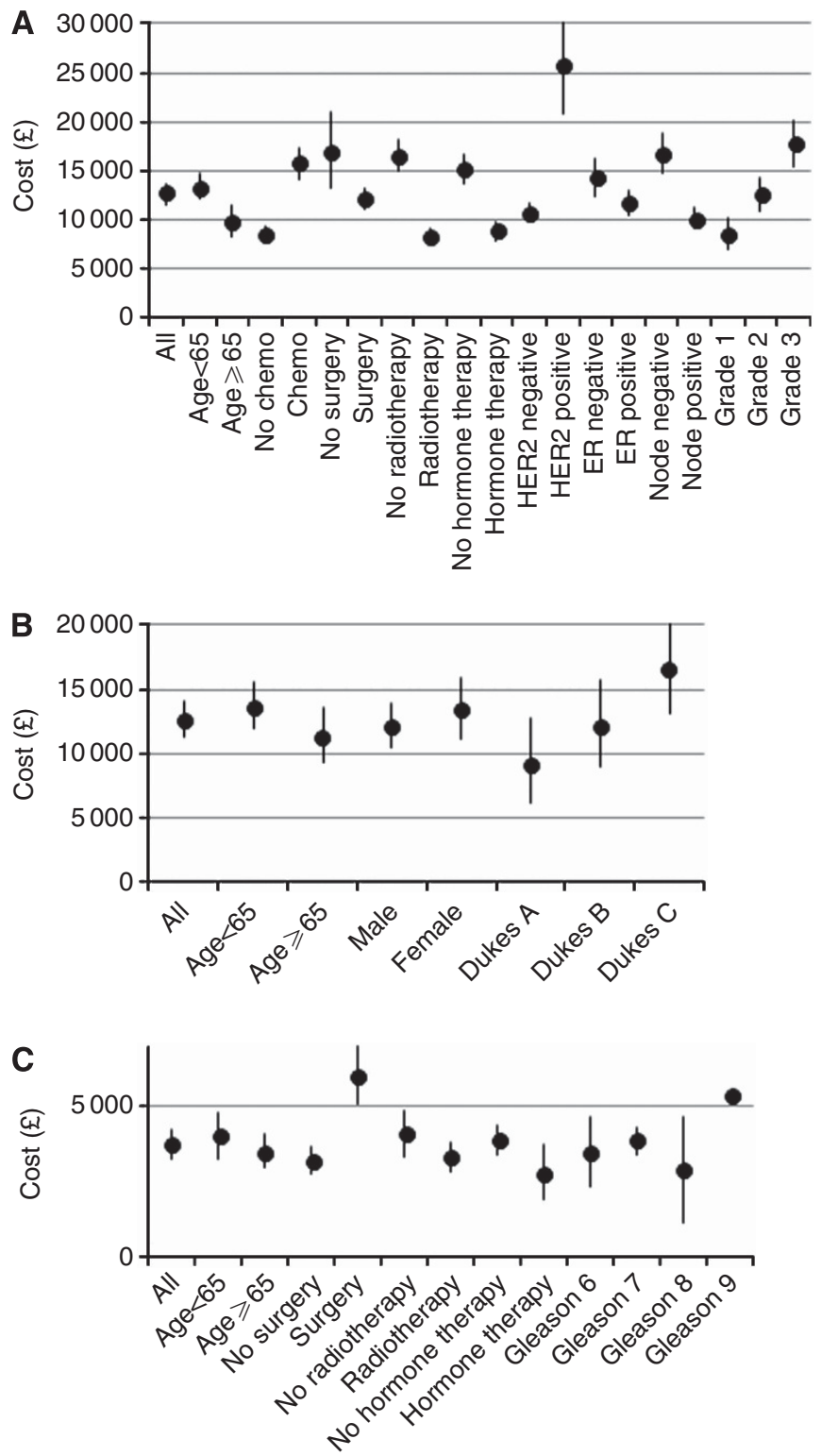

Figure 3. Mean 15 -month costs with $95 \%$ confidence intervals for subgroups (A) Breast cancer, (B) colorectal cancer, (C) prostate cancer. costs increase with disease stage (Figure 3). Tables 2 and 3 include the univariate and multivariate analyses, respectively, predicting 15-month costs. In each case, disease stage appears to be the strongest predictor of costs.

Utility. Figure 4 depicts the mean EQ-5D score at 6, 9 and 15 months for each of the three cancer types. The mean EQ-5D scores for patients with each cancer type increased over time, generally plateauing after 1 year from diagnosis. Breast cancer patients had the worst utility and the smallest improvements over time, which may reflect more aggressive adjuvant treatment over a longer time period compared with the two other cancer types. Older breast cancer patients also had higher utility than younger patients across the three time points, possibly for the same reasons. There was a trend suggesting that those living in areas of higher deprivation (lower IMD groups) had lower QoL scores compared with those living in more affluent areas. However, the multivariate regression of the EQ-5D scores (results in Supplementary Material) found no significant predictors of utility at any time point for any cancer.

A full breakdown of the cumulative costs and EQ-5D score at 6, 9 and 15 months from diagnosis for each tumour type, clinical subgroups and treatment modalities is provided in the Supplementary Appendix. EQ-5D score at T3 demonstrated only minimal correlation with cumulative costs with a Pearson's correlation coefficient of -0.06 for breast cancer, -0.20 for colorectal cancer and -0.10 for prostate cancer. A low EQ-5D score at T1 was associated with higher 15 month cumulative costs but this only reached statistical significance in univariate and multivariate analysis for colorectal cancer (Tables 2 and 3).

Comparisons with population norms indicated that breast cancer patients had significantly lower EQ-5D score than an ageand sex-matched reference population. Conversely, prostate cancer patients were found to have significantly higher scores than the reference population. No significant difference was found for colorectal cancer patients (Table 4).

\section{DISCUSSION}

Traditionally cost and cost-effectiveness analyses in the United Kingdom have used techniques such as hand-searching patient records, asking patients to complete resource use questionnaires or use of a combination of different methods from diverse sources in order to collect cost and outcomes data (Karnon et al, 2007). For studies with large sample sizes and longitudinal analyses, these methods are particularly time consuming and have the potential 
for bias due to discrepancies in records both within and between facilities. More recently, use of Hospital Episode Statistics (HES) has gained popularity within cost analysis (Gaughan et al, 2012). HES provides electronic access to over 125 million outpatient, inpatient and accident and emergency attendances in England and is increasingly used for economic analysis, negating to some extent the need to manually collect details of resource use from patient records. However, there has been debate over the completeness of HES data and constraints in the range of activity covered (Spencer and Davies, 2012). In addition, manual hand searching, patient questionnaires and HES all require unit costs to be assigned to the resource use, described as a 'top-down' costing approach. Use of

\begin{tabular}{|c|c|c|c|c|}
\hline & Coefficient & $\operatorname{Exp}($ coeff) & s.e. & $P$-value \\
\hline \multicolumn{5}{|l|}{ Breast cancer } \\
\hline Age & -0.015 & 0.985 & 0.004 & $<0.001$ \\
\hline$I M D \geqslant 3$ & 0.064 & 1.066 & 0.093 & 0.491 \\
\hline HER2 positive & 0.1454 & 1.157 & 0.083 & 0.082 \\
\hline HR positive & -0.2032 & 0.816 & 0.089 & 0.024 \\
\hline Lymph node positive & 0.5516 & 1.736 & 0.089 & $<0.001$ \\
\hline Grade 3 & 0.520 & 1.682 & 0.100 & $<0.001$ \\
\hline EQ-5D (at T1) & -1.020 & 0.361 & 0.363 & 0.006 \\
\hline \multicolumn{5}{|l|}{ Colorectal cancer } \\
\hline Age & -0.0135 & 0.987 & 0.027 & 0.006 \\
\hline Gender (female) & 0.1178 & 1.125 & 0.399 & 0.139 \\
\hline $\mathrm{IMD} \geqslant 3$ & 0.1202 & 1.128 & 0.190 & 0.53 \\
\hline Dukes stage $C$ & 0.5291 & 1.697 & 0.173 & 0.003 \\
\hline EQ-5D (at T1) & -0.202 & 0.817 & 0.246 & 0.413 \\
\hline \multicolumn{5}{|l|}{ Prostate cancer } \\
\hline Age & -0.0097 & 0.990 & 0.420 & 0.012 \\
\hline$I M D \geqslant 3$ & -0.1033 & 0.902 & 0.179 & 0.566 \\
\hline Gleason score $\geqslant 7$ & 0.4834 & 1.622 & 0.179 & 0.008 \\
\hline EQ-5D (at T1) & -0.433 & 0.649 & 0.448 & 0.336 \\
\hline
\end{tabular}

PLICS data for this type of economic evaluation is based on local 'bottom-up' costing techniques, where the costs of specific procedures or care episodes reflect the real local expenditure required to provide them. Analysis using a PLICS database is less onerous, time-consuming and costly than hand searching patient records and is unlikely to suffer potential difficulties associated with recall bias. Local unit costs are included in each PLICS database and the granularity and range of the data is likely to have fewer constraints than HES data.

Table 3. Multivariate regression analyses for 15 month costs (log-scale)

\begin{tabular}{|c|c|c|c|c|}
\hline & Coefficient & Exp(coeff) & s.e. & $P$-value \\
\hline \multicolumn{5}{|l|}{ Breast cancer } \\
\hline (intercept) & 9.207 & 9967 & 0.259 & \\
\hline Age & -0.008 & 0.992 & 0.003 & 0.016 \\
\hline $\mid M D \geqslant 3$ & 0.034 & 1.035 & 0.078 & 0.663 \\
\hline HER2 positive & 0.358 & 1.430 & 0.093 & $<0.001$ \\
\hline HR positive & -0.099 & 0.906 & 0.090 & 0.271 \\
\hline Lymph node positive & 0.556 & 1.744 & 0.083 & $<0.001$ \\
\hline Grade $\geqslant 3$ & 0.454 & 1.575 & 0.091 & $<0.001$ \\
\hline EQ-5D (at T1) & -0.147 & 0.863 & 0.212 & 0.488 \\
\hline \multicolumn{5}{|l|}{ Colorectal cancer } \\
\hline (intercept) & 9.298 & 10916.17 & 0.647 & \\
\hline Age & -0.005 & 0.996 & 0.009 & 0.551 \\
\hline Gender (female) & 0.010 & 1.010 & 0.181 & 0.957 \\
\hline$I M D \geqslant 3$ & 0.113 & 1.120 & 0.175 & 0.520 \\
\hline Dukes stage $C$ & 0.528 & 1.696 & 0.188 & 0.006 \\
\hline EQ-5D (at T1) & -1.620 & 0.162 & 0.595 & 0.009 \\
\hline \multicolumn{5}{|l|}{ Prostate cancer } \\
\hline (intercept) & 8.593 & 5393.77 & 0.794 & \\
\hline Age & -0.013 & 0.987 & 0.012 & 0.287 \\
\hline $\mathrm{IMD} \geqslant 3$ & -0.133 & 0.875 & 0.191 & 0.486 \\
\hline Gleason score $\geqslant 7$ & 0.497 & 1.644 & 0.183 & 0.008 \\
\hline EQ-5D (at T1) & -0.256 & 0.774 & 0.472 & 0.590 \\
\hline
\end{tabular}
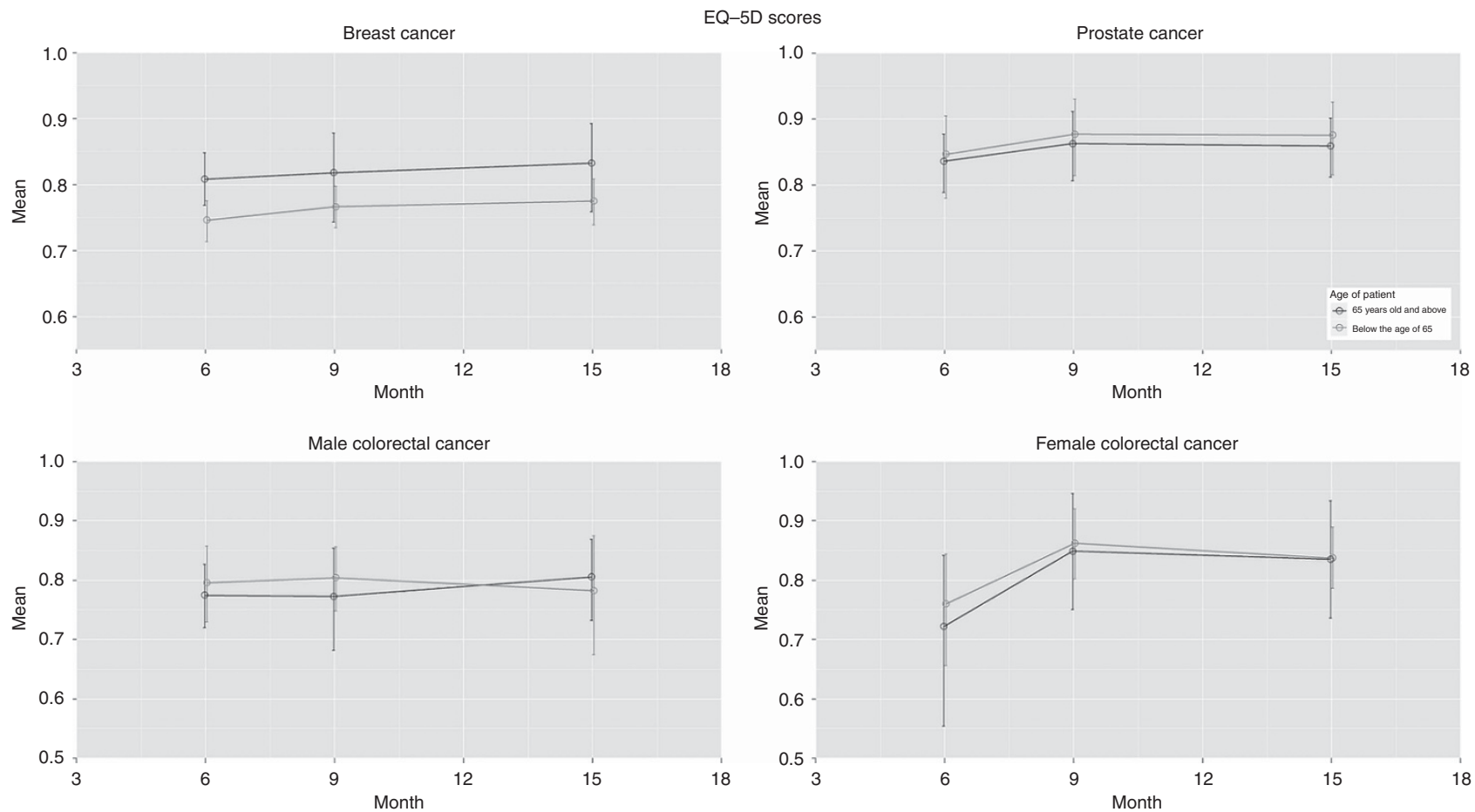

Figure 4. EQ-5D utility values by age, gender and tumour site at T1, T2 and T3. 
Table 4. Comparison of EQ-5D utility scores with population norms

\begin{tabular}{|c|c|c|c|}
\hline & Study sample & $\begin{array}{l}\text { Reference } \\
\text { population }\end{array}$ & $P$-value \\
\hline \multicolumn{4}{|c|}{ Breast } \\
\hline T1 & 0.755 & 0.823 & 0.000 \\
\hline $\mathrm{T} 2$ & 0.776 & 0.826 & 0.002 \\
\hline T3 & 0.785 & 0.826 & 0.018 \\
\hline \multicolumn{4}{|c|}{ Colorectal } \\
\hline $\mathrm{T} 1$ & 0.765 & 0.793 & 0.130 \\
\hline $\mathrm{T} 2$ & 0.802 & 0.793 & 0.598 \\
\hline T3 & 0.812 & 0.794 & 0.362 \\
\hline \multicolumn{4}{|c|}{ Prostate } \\
\hline T1 & 0.838 & 0.780 & 0.002 \\
\hline $\mathrm{T} 2$ & 0.868 & 0.780 & 0.000 \\
\hline T3 & 0.868 & 0.779 & 0.000 \\
\hline
\end{tabular}

In the United Kingdom, the PLICS initiative led to coordinated local piloting in 2009 with the primary objective of providing NHS organisations a better understanding of their drivers of costs (Department of Health, 2011). The intention of this system is to provide an electronic means by which to measure the resources consumed by individual patients. Such data may then be used to understand variations in services. When linked with clinical care and outcomes data, improved clinical ownership of resource decisions and evidence-based analysis also becomes possible (Francisci et al, 2013). PLICS is not compulsory across the NHS, and by 2010 few Trusts had implemented the system. Early indications suggest that it is a useful tool to provide accurate data on spending against income (Blunt and Bardsley, 2012). This is the first study to assign costs to the clinical cancer care pathway using linkage between PLICS and clinical data sets. It also has the added advantage of linked QoL data, providing proof-of-concept for a comprehensive routine electronic data set for technology evaluation.

This study adds substantially to the current limited literature on the costs of hospital-based cancer care using robust, efficient and reproducible methods. To our knowledge this is the first UK study to report costs in this manner for the initial year after diagnosis and certainly the largest study of its kind to date. Two previous studies have looked at the costs of recurrent breast cancer with estimates between $£ 12000$ and $£ 25000$ for the first year after diagnosis of a recurrence in patients with a previously treated breast cancer (Karnon et al, 2007; Thomas et al, 2009). Both studies use a top-down HRG-based costing method. This compares with our study's headline 15-month cost for new breast cancer patients of $£ 12595$.

The cost analysis was based on the data from one of the biggest NHS trusts in the country, which offers a range of both general and specialist hospital services. The results are therefore likely to be broadly generalisable across the UK population to similar sized populations. Care should be taken when attempting to apply these cost results in a non-UK context, as the specific configuration of individual national health-care service provision - which has a major impact on how and where costs are likely to be incurred can vary significantly from country to country. An advantage of this study is that it enables adjustment of both costs and EQ-5D scores based on clinical and demographic factors, allowing greater representations of local populations with well-defined characteristics.

Overall, this analysis found that baseline staging and related clinical characteristics were the strongest predictors of hospital costs. Within breast cancer significant predictors were lymph node status, grade and molecular markers (HER2 and hormone status); for colorectal cancer, Dukes classification and for prostate cancer the Gleason score. Sociodemographic variables were of less importance as predictors of cost. There was no clear association between treatment costs and IMD. This is surprising given that health inequalities have previously been seen to be associated with poorer health and health outcomes and higher treatment costs (Marmot et al, 2010). It may, however, be explained by a limitation of the study, whereby all people involved in ePOCS had to be able to access the internet. Inevitably, this meant that the trend common in routine clinical trials, whereby fewer older people living in areas of greater deprivation enroll in studies, was exacerbated in this study (Sateren, 2002; Murthy et al, 2004). There was a significant difference in IMD quintile between those who consented and refused study participation $(P<001)$, and IMD quintile was the only significant predictor of retention in a regression analyses. In addition, our analysis showed no correlation between IMD and staging in contrast to evidence to suggest IMD predicts clinical outcome (Downing et al, 2007).

Our univariate analyses showed significant differences in costs by age, but these differences were no longer significant (at the $99 \%$ level) in the multivariate analyses. Despite the lack of statistical significance, a clear trend exists suggesting that older patients (65 and over) are associated with lower costs than younger patients. In the case of breast cancer, this may be explained by younger patients presenting with higher disease stage, as well as more aggressive treatment of younger patients. In colorectal and prostate cancer it is unclear why this might be and whether this is related to demand-side (patients actively consuming more health care resources-e.g., contacting the doctor more frequently) or supply-side factors (health-care professionals providing more health care resources-e.g., conducting more tests or suggesting more frequent visits). The absence of information about comorbidity is a clear limitation of this study as it is likely that comorbidity contributes to differences in costs between age groups.

The multivariate regression of the EQ-5D scores found no significant predictors of QoL at any time-point for the three cancer types. The lack of significance may be a function of the relatively limited sample size, particularly for the EQ-5D analysis due to the limitation of missing data. The descriptive analysis on the EQ-5D by subgroup did provide some interesting results. In line with expectations, the QoL for patients with the three cancer types increased over time from diagnosis and radical treatment. Breast cancer patients appear to have the worst QoL and the smallest improvements in QoL over time. This may be related to the continuing psychological impact of mastectomy, especially in a sample that is young relative to the other cancer-type patients. There was the interesting finding that younger women with breast cancer have worse QoL than older women. This confirms the findings in this regard of a number of other studies (Calman, 1984; Hopwood et al, 2007). In contrast, conventional wisdom in nonbreast cancer patients based on many analyses of EQ-5D data, including population norms and Health Survey for England data, has concluded that QoL declines with age (Maheswaran et al, 2013). Indeed, we see in the prostate and colorectal cancer groups that older patients have lower EQ-5D scores, even when stratified by gender. It is not clear why this QoL reversal by age group exists in breast cancer. It is possible that the impact of cancer is greater in younger patients due to greater psychological distress, or appears greater due to questionnaire responses being reference based (to the health of similarly aged-peers) or expectation-based. A number of mean between-group differences in QoL appeared non-trivial and in the order of magnitude of a difference that could be considered important (between 0.06 and 0.12) (Pickard et al, 2007a). These include the differences between breast and prostate cancer patients, differences between age groups in breast cancer and between the highest and lowest IMD groups. The QoL of the three sets of cancer patients appears roughly in line with population norms with the exception that younger breast cancer 
patients experience a decrement and the patients with prostate cancer have consistently higher scores. The colorectal cancer patients are almost the same as the population norms. The recruitment and retention within the ePOCS study is biased owing to both deprivation and age, in common in many trials and exaggerated in ePOCS owing to the reliance on information technology. This may explain higher than expected QoL. The association seen between T1 EQ-5D scores and cumulative costs is intuitive given that more intensive treatments such as chemotherapy and radiotherapy may cost more and increase morbidity.

LTHT's PLICS system is constructed using nationally recognised costing principles and methods, supplemented where appropriate by locally determined rules and arrangements relevant and appropriate to PLICS, and having been determined in consultation with divisional clinical, operational and finance representatives initially and since by regular review. Effort to date has predominantly been focussed on refining the inputs to the system and, at the time of writing, there has been no systematic, widespread review of PLICS outputs across LTHT among operational and clinical staff. This is something which, following a recent Trust restructuring and the creation of Clinical Service Units, the Trust is now embarking upon using 2012-2013 PLICS data. Until this systematic validation takes place, LTHT PLICS data must be treated with caution. In addition, the Trust is conscious of a number of areas of NHS service provision in which the linking of costs to patients is still not possible, such as catering services and housekeeping; this may impact differentially on services evaluated.

This analysis considered hospital post-diagnosis costs over a 15-month follow-up period. A full analysis of costs requires additional consideration of both primary and community care costs, as well as costs incurred pre-diagnosis and in the longer term. We will be attempting to quantify these additional costs in future planned analyses.

This paper has described an analysis based on data generated by using a novel method of capturing patient-reported outcome data and linking that with clinical and cost data from hospitals. The feasibility and utility of such data linkage now being evident, further efforts to routinely collect and link such data is encouraged. The results described here will be of use to health economic modellers requiring cost and utility estimates to populate decisionanalytical models. The results have implications for health economic analysis and modelling in cancer. First, costs decline rapidly after the initial treatment phase but have small peaks around the routine visit time points; thus analysts should have differential cost estimates in year 1 vs subsequent years. Unsurprisingly, costs differ not only by disease stage but also more unexpectedly by age with younger patients being associated with greater costs. The latter point is worthy of further investigation. The QoL of patients recovering from cancer does not appear substantively different from age-specific population norms with the exception of younger women with breast cancer, although this finding may be a result of potential patient selection bias as previously discussed. Future economic analyses of breast cancer interventions should bear in mind the QoL decrement that accompanies breast cancer in younger groups in addition to the time-varying and subgroup-varying nature of secondary healthcare costs.

\section{ACKNOWLEDGEMENTS}

We would like to thank the Corporate Finance Department of LTHT including Wendy Allott and Joe Selfridge who provided data from the LTHT PLICS. We note that they take no responsibility for the analysis or interpretation of the data. This work was funded by Macmillan Cancer Support.

\section{REFERENCES}

Ashley L, Jones H, Forman D, Newsham A, Brown J, Downing A, Velikova G, Wright P (2011a) Feasibility test of a UK-scalable electronic system for regular collection of patient-reported outcome measures and linkage with clinical cancer registry data: the electronic Patient-reported Outcomes from Cancer Survivors (ePOCS) system. BMC Med Inf Decis Making 11: 66 .

Ashley L, Jones H, Thomas J, Forman D, Newsham A, Morris E, Johnson O, Velikova G, Wright P (2011b) Integrating cancer survivors' experiences into UK cancer registries: design and development of the ePOCS system (electronic Patient-reported Outcomes from Cancer Survivors). Br J Cancer 105: S74-S81.

Ashley L, Jones H, Thomas J, Newsham A, Downing A, Morris E, Brown J, Velikova G, Forman D, Wright P (2013) Integrating patient reported outcomes with clinical cancer registry data: a feasibility study of the electronic Patient-Reported Outcomes From Cancer Survivors (ePOCS) system. J Med Internet Res 15: e230.

Black N (2013) Patient reported outcome measures could help transform healthcare. BMJ 346: f167.

Blunt I, Bardsley M (2012) Patient-Level Costing: Can it Yield Efficiency Savings? London.

Brown ML, Riley GF, Potosky AL, Etzioni RD (1999) Obtaining long-term disease specific costs of care: application to Medicare enrollees diagnosed with colorectal cancer. Med Care 37: 1249-1259.

Calman KC (1984) Quality of life in cancer patients-an hypothesis. J Med Ethics 10: 124-127.

Department for Communities and Local Government (2011) English Indices of Deprivation 2010: Guidance Document. Crown Copyright: London.

Department of Health (2011) Patient Level Information \& Costing Systems (PLICS) \& Reference Costs Best Practice Guide London.

Department of Health Payment by Results team (2012) A Simple Guide to Payment by Results London.

De Oliveira C, Bremner KE, Pataky R, Gunraj N, Chan K, Peacock S, Krahn MD (2013) Understanding the costs of cancer care before and after diagnosis for the 21 most common cancers in Ontario: a population-based descriptive study. CMAJ Open 1: E1-E8.

Downing A, Prakash K, Gilthorpe MS, Mikeljevic JS, Forman D (2007) Socioeconomic background in relation to stage at diagnosis, treatment and survival in women with breast cancer. Br J Cancer 96: 836-840.

Drummond MF, Sculpher MJ, Torrance GW, O’Brien B, Stoddar GL (2005) Methods For the Economic Evaluation of Health Care Programmes. 3rd edn, Oxford University Press: Oxford, UK.

Francisci S, Guzzinati S, Mezzetti M, Crocetti E, Giusti F, Miccinesi G, Paci E, Angiolini C, Gigli A (2013) Cost profiles of colorectal cancer patients in Italy based on individual patterns of care. BMC Cancer 13: 329.

Gaughan J, Mason A, Street A, Ward P (2012) English hospitals can improve their use of resources: an analysis of costs and length of stay for ten treatments.

Glaser AW, Fraser LK, Corner J, Feltbower R, Morris EJA, Hartwell G, Richards M (2013) Patient-reported outcomes of cancer survivors in England 1-5 years after diagnosis: a cross-sectional survey. BMJ Open 3: e002317.

Gudex C, Kind P, Williams A (1995) A Social Tariff for EuroQol: Results From a UK General Population Survey. Univerisity of York, Centre for Health Economics: UK.

Hopwood P, Haviland J, Mills J, Sumo G, M Bliss J (2007) The impact of age and clinical factors on quality of life in early breast cancer: an analysis of 2208 women recruited to the UK START Trial (Standardisation of Breast Radiotherapy Trial). Breast 16: 241-251.

Karnon J, Kerr GR, Jack W, Papo NL, Cameron DA (2007) Health care costs for the treatment of breast cancer recurrent events: estimates from a UK-based patient-level analysis. Br J Cancer 97: 479-485.

Kind P, Dolan P, Gudex C, Williams A (1998) Variations in population health status: results from a United Kingdom national questionnaire survey. BMJ 316: 736-741.

Krahn MD, Zagorski B, Laporte A, Alibhai SMH, Bremner KE, Tomlinson G, Warde P, Naglie G (2010) Healthcare costs associated with prostate cancer: Estimates from a population-based study. BJU Int 105: 338-346.

Maheswaran H, Petrou S, Rees K, Stranges S (2013) Estimating EQ-5D utility values for major health behavioural risk factors in England. J Epidemiol Community Health 67: 172-180. 
Mariotto AB, Yabroff KR, Shao Y, Feuer EJ, Brown ML (2011) Projections of the cost of cancer care in the United States: 2010-2020. J Natl Cancer Inst 103: $117-128$.

Marmot M, Atkinson T, Bell J (2010) Fair society, healthy lives. Available at http://www.instituteofhealthequity.org/projects/fair-society-healthy-livesthe-marmot-review.

Murthy VH, Krumholz HM, Gross CP (2004) Participation in cancer clinical trials: race-, sex-, and age-based disparities. JAMA 291: 2720-2726.

Newsham AC, Johnston C, Hall G, Leahy MG, Smith AB, Vikram A, Donnelly AM, Velikova G, Selby PJ, Fisher SE (2011) Development of an advanced database for clinical trials integrated with an electronic patient record system. Comput Biol Med 41: 575-586.

Pickard AS, Neary MP, Cella D (2007a) Estimation of minimally important differences in EQ-5D utility and VAS scores in cancer. Heal Qual Life Outcomes 5: 70

Pickard AS, Wilke CT, Lin HW, Lloyd A (2007b) Health utilities using the EQ-5D in studies of cancer. Pharmacoeconomics 25: 365-384.

R Development Core Team (2009) R: A language and environment for statistical computing. R Foundation for Statistical Computing: Vienna, Austria, ISBN 3-900051-07-0. http://www.R-project.org.

Sateren WB (2002) How sociodemographics, presence of oncology specialists, and hospital cancer programs affect accrual to cancer treatment trials. J Clin Oncol 20: 2109-2117.
Spencer SA, Davies MP (2012) Hospital episode statistics: improving the quality and value of hospital data: a national internet e-survey of hospital consultants. BMJ Open 2: e001651.

The EuroQol Group (1990) EuroQol-a new facility for the measurement of health-related quality of life. Health Policy (New York) 16: 199-208.

Thomas RJ, Williams M, Marshall C, Glen J, Callam M (2009) The total hospital and community UK costs of managing patients with relapsed breast cancer. Br J Cancer 100: 598-600.

Tilson L, Sharp L, Usher C, Walsh C, S W, O'Ceilleachair A, Stuart C, Mehigan B, John Kennedy M, Tappenden P, Chilcott J, Staines A, Comber H, Barry M (2012) Cost of care for colorectal cancer in Ireland: a health care payer perspective. Eur J Health Econ 13: 511-524.

Vogl M (2012) Improving patient-level costing in the English and the German "DRG"system. Health Policy (New York) 109(3): 290-300.

Yabroff KR, Lamont EB, Mariotto A, Warren JL, Topor M, Meekins A, Brown ML (2008) Cost of care for elderly cancer patients in the United States. J Natl Cancer Inst 100: 630-641.

This work is published under the standard license to publish agreement. After 12 months the work will become freely available and the license terms will switch to a Creative Commons AttributionNonCommercial-Share Alike 4.0 Unported License.

Supplementary Information accompanies this paper on British Journal of Cancer website (http://www.nature.com/bjc) 